\title{
Health status and its socio-economic covariates in the older population in Poland - the assumptions and methods of the nationwide, cross-sectional PolSenior2 survey
}

\author{
Łukasz Wierucki ${ }^{1}$, Hanna Kujawska-Danecka², Małgorzata Mossakowska³, Tomasz Grodzicki ${ }^{4}$, \\ Piotr Błędowski ${ }^{5}$, Jerzy Chudek ${ }^{6}$, Tomasz Kostka ${ }^{7}$, Andrzej Więcek ${ }^{8}$, Adam Hajduk ${ }^{2}$, Piotr Bandosz ${ }^{1}$, \\ Paweł Zagożdżon ${ }^{9}$, Bogdan Wojtyniak ${ }^{10}$, Tomasz Zdrojewski ${ }^{1}$
}

'Department of Preventive Medicine and Education, Medical University of Gdansk, Gdansk, Poland

${ }^{2}$ Department of Internal Medicine, Connective Tissue Diseases and Geriatrics,

Medical University of Gdansk, Gdansk, Poland

${ }^{3}$ International Institute of Molecular and Cell Biology, Warsaw, Poland

${ }^{4}$ Department of Internal Medicine and Gerontology, Jagiellonian University

Medical College, Krakow, Poland

${ }^{5}$ Institute of Social Economy, Warsaw School of Economics, Warsaw, Poland

${ }^{6}$ Department of Internal Medicine and Oncological Chemotherapy, Medical University

of Silesia, Katowice, Poland

${ }^{7}$ Department of Geriatrics, Medical University of Lodz, Lodz, Poland

${ }^{8}$ Department of Nephrology, Transplantation and Internal Medicine,

Medical University of Silesia, Katowice, Poland

${ }^{9}$ Department of Hygiene and Epidemiology, Medical University of Gdansk, Gdansk, Poland

${ }^{10}$ Department of Population Health Monitoring and Analysis, National Institute of Public Health-National Institute of Hygiene, Warsaw, Poland

Submitted: 17 August 2020; Accepted: 7 November 2020

Online publication: 13 November 2020

Arch Med Sci 2022; 18 (1): 92-102

DOI: https://doi.org/10.5114/aoms.2020.100898

Copyright $\odot 2020$ Termedia \& Banach

\section{Abstract}

Introduction: Population ageing constitutes an increasing medical, social, and economic burden worldwide. Optimal senior policy should be based on well-assessed knowledge on the prevalence and control of age-related diseases, multimorbidity, disabilities, and their social determinants. The objective of this paper is to describe the assumptions, methods, and sampling procedures of the PolSenior2 survey, which was aimed at characterising the health status of old and very-old adults in Poland.

Material and methods: The project was conducted in the period 20182019 as a cross-sectional survey of a representative sample of people aged 60 years and over. Subjects were selected using three-stage stratified and proportional random sampling in seven equally sized $(n=850)$ age groups. The study protocol consisted of face-to-face interviews, specific geriatric scales and tests, and anthropometric and blood pressure measurements performed by well-trained nurses at participants homes as well as blood and urine sample laboratory tests.

Results: In the Polsenior2 study a group of 5987 subjects underwent the questionnaire parts of the survey, and almost all $(n=5823)$ agreed to blood or urine sample collection.

Conclusions: In recent decades several studies focused on various aspects of elderly health and life conditions had been carried out in Poland and Central and Eastern Europe. However, none of them is so complex and has covered so many issues as PolSenior2, which is the largest study devoted to

\section{Corresponding author:}

Dr. Hanna Kujawska-Danecka Department of Internal Medicine, Connective Tissue Diseases and Geriatrics Medical University of Gdansk Gdansk, Poland Phone: +48583492524 E-mail: hanna.kujawska@ gumed.edu.pl 
the health status of older persons in Poland and one of the largest and the most comprehensive in Europe. The results of the study will help to improve health policy targeted at the elderly population in Poland.

Key words: ageing, cross-sectional survey, national, older population health, PolSenior2.

\section{Introduction}

Fast demographic ageing of developed societies is one of the most important upcoming challenges for health and social care systems and a potential barrier for economic growth. The population of people aged 65 and older in Europe will increase from $17 \%$ in 2015 to almost $30 \%$ in 2050 , while the number of people aged 80 and older will rise even faster ("double ageing") [1]. In Poland, the percentage of citizens aged 65 years or more in 2050 is expected to reach $32.7 \%$ [2], while almost one third of them will be at least 80 years old (10.0\% of the whole population), and the number of centenarians will increase to almost 60,000 [2]

The increase in the number of old and very old people will result in growing demand for medical and social services because aging is accompanied by comorbidities, functional impairment, and disability. Providing these services is more expensive in older people. The mean hospitalisation costs of patients aged 65 years and older in Poland are higher than for younger patients due to longer mean length of hospitalisation and more complex and expensive treatment [3]. As shown in the PolSenior survey performed in the period 2007-2010, functional dependence was increasing with age from $17 \%$ among those aged $65-69$ years to $65 \%$ among the oldest-old (aged 90+ years) [4]. To reduce the social and economic burden of an aging society it is necessary to define and characterise co-variates of life in good health. In Poland in 2016 life expectancy for people at the age of 65 years was 20.5 years for women and 16.0 for men, but healthy life expectancy was only 8.9 and 8.2 years, respectively (average values for EU countries were 10.1 and 9.8 years for women and men) [5]. This results in about $50 \%$ of expected life in poor health.

The PolSenior2 project is a continuation of the multicentre, publicly funded survey PolSenior, conducted in 2007-2011 (referred to as PolSenior1). It was the largest ever scientific research program focused on health of old adults in Poland. The current survey is commissioned by the Ministry of Health in the frame of the National Health Program 2016-2020 (NPZ.CO5_4.2_1_2016, Operational objective: Promotion of healthy and active aging). In the PolSenior2 project a new cohort has been drawn. Its main aim is to assess the current health and socio-economic status of the Polish older population with special emphasis on the oldest-old.
One of the goals is to assess the prevalence and control of age-related diseases and the "geriatric giants" (immobility, instability, incontinence, sensory deficiency, cognition and mood disorders), which lead to frailty, disability, and dependence. Monitoring of healthy behaviours and identifying socio-economic factors favouring successful aging will allow the risk of developing disability and the quality of routine health maintenance in the care of older adults to be assessed [6, 7]. Because polypragmasy and adverse drug reactions remain an important issue in geriatric care, pharmacotherapy and medical adherence will be examined. The additional purpose of the study is to evaluate the utilisation and access to health care and social services in respect to needs for assistance and long-term care, as well as the level and different forms of these needs.

Because the PolSenior2 project was started 10 years after PolSenior1 [8], it will allow the analysis of changes and the prediction of epidemiological trends in the aging Polish society. Moreover, the use of validated, standardised tools in the geriatric assessment will give an opportunity to compare results of the PolSenior2 project with those obtained in other countries.

\section{Material and methods}

\section{Program description}

The protocol of the PolSenior2 study is based on the protocol of the PolSenior1 project [8]. However, the experience gained during implementation of the former project as well as new research findings, guidelines, emerging topics in geriatric medicine, such as sarcopenia and frailty, and new elements required by the Ministry of Health have been included in the current protocol, broadening significantly the scope of planned analyses [9-12].

The field work was preceded by sample drawing and subjects' recruitment. Respondents were visited at their homes, and medical and socioeconomic surveys were conducted. There were also measurements taken of blood pressure (BP), hand grip strength, anthropometric parameters, and body composition. Blood and urine samples were collected.

\section{Subject recruitment}

A multistage stratified and clustered sampling design was used. The pattern for respondent se- 
lection was designed to obtain a sample representative for old and very-old citizens in Poland, with 99\% of them being Caucasians. The first stage draw identified local administrative units, including urban, rural, and urban-rural municipalities in each of 16 voivodships (regions). Towns and cities were divided into five groups, depending on size: $\leq 20,000$ residents, $20,000-50,000$ residents, 50,000-200,000 residents, 200,000-500,000 residents, and $>500,000$ residents. The final number of territorial strata was 78 . The number of respondents to be drawn in each stratum was proportional to its population size and was based on the population structure in December 2016 [13]. Then, 137 municipalities were drawn in previously defined strata, with the probability proportional to the size of the population aged 60+ years in a particular municipality.

In the second step, the clusters were created by random selection of villages in rural municipalities

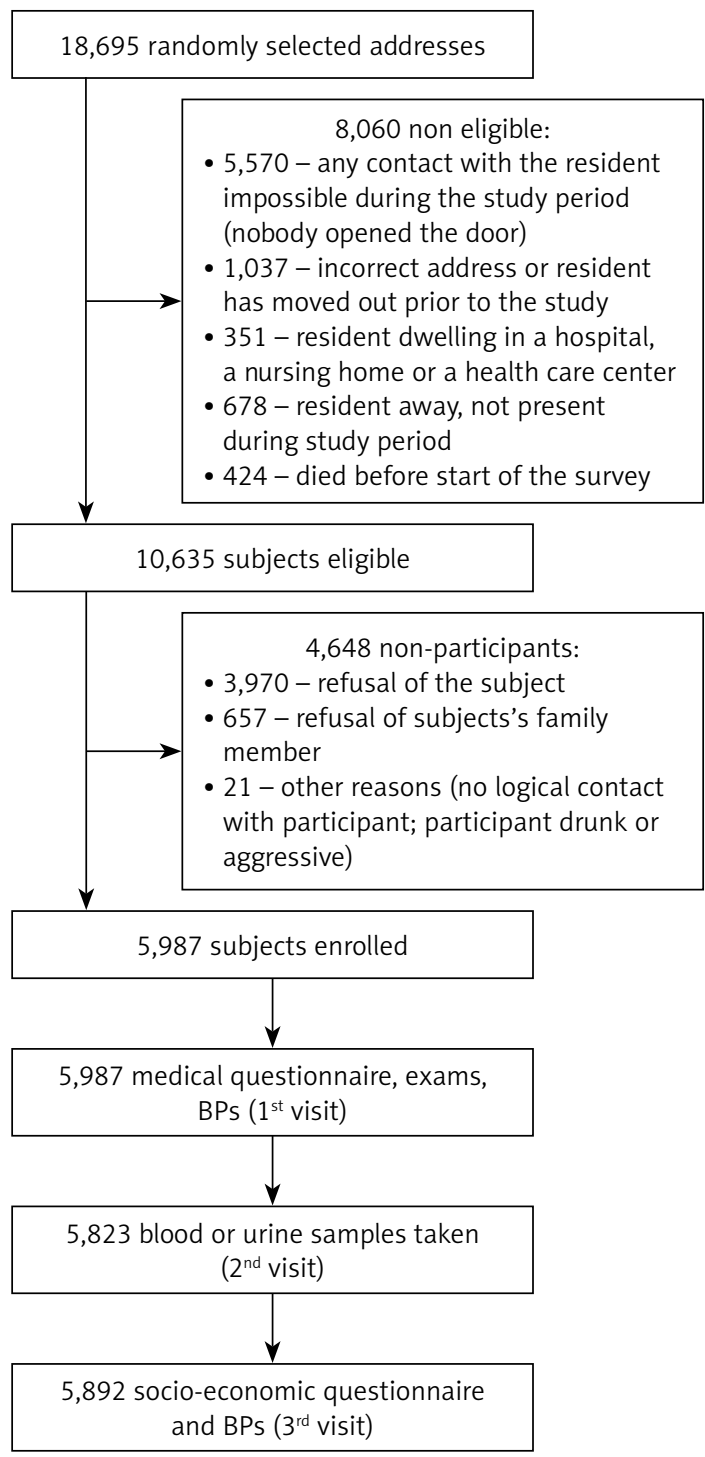

Figure 1. The PolSenior2 study flowchart and cities in urban municipalities. The sampling frame was the registry of cities and villages in the previously selected municipalities. During the third stage, individual survey participants were drawn from the population of previously selected villages/cities, using the national PESEL registry as the sampling frame (PESEL - Universal Electronic System for Registration of the Population, held by the Ministry of Digital Affairs). Roughly equal numbers of study subjects were drawn in each 5-year age and sex group. This overrepresentation of the oldest subjects in the study sample (as compared to the actual structure of Polish society) was intended to increase statistical power for analyses performed in the oldest age group. A three-stage stratified sampling resulted in a list of 6006 subjects composed of seven roughly equally sized $(n=850)$ age cohorts $(60-65,65-69,70-74$, $75-79,80-84,85-89$, and 90+ years). Additional reserve participants were drawn for each study subject. In the case of non-respondence (refusal of participation or when a respondent died, moved to a different place, or had invalid address data), reserve participants were interviewed in the predefined sequence.

The nurse's tasks included visiting the selected household three times at different times of the day. If the respondent was absent and it was possible to establish a different location of the respondent in the same commune, the nurse was obliged to go there and invite the person to be examined. The exceptions were hospitals, nursing homes, hospices, and prisons. The response rate was calculated as the percentage of people (and addresses) who were included in the study in relation to the total of randomly selected respondents with whom contact was possible. The response rate calculated on the basis of the above criteria was $52 \%$ in the PolSenior 2 project. This ratio, also taking into account the respondents who could not be found at home (no one opened the door), would be $36 \%$. The study flow chart is presented in Figure 1.

\section{Field work process}

The study protocol consisted of three paper-version questionnaires (face-to-face interviews), anthropometric and blood pressure measurements performed during three visits at participants homes, and laboratory tests. Interviewers were recruited among professionally active nurses who worked mostly within local communities. All of them underwent special training for the purposes of the PolSenior2 project.

The medical part of the questionnaire was completed by a nurse during the first visit. Blood and urine samples as well as an additional questionnaire filled in by the respondent were collected during the 
second visit. The socio-economic part of the questionnaire was completed during the third visit.

\section{Questionnaire and selected geriatric scales and tests}

To improve the quality of data collection a vast majority of questions were formed as closed questions. The survey included questions about facts and opinions. If the health condition of the respondent did not allow him or her to actively participate in the survey, the information about facts could be obtained from family members or caregivers. The questions about opinions, as well as selected scales, were addressed solely to respondents.

\section{Medical Questionnaire}

Medical part contained general and detailed questions about present health status and history of diseases, as well as hospitalizations. A detailed list of currently used prescriptions, over-thecounter (OTC) medications, and supplements was completed. Participants were also asked questions concerning motivation for taking OTC drugs, medication compliance, and adverse drug reactions.

A rough evaluation of the respondents' hearing and vision was performed before the assessment of cognitive functions. The Mini Mental State Examination (MMSE) and the Clock Drawing Test were used to screen for dementia $[14,15]$. A short (15-item) version of the Geriatric Depression Scale (GDS) was completed to identify subjects with mood disorders [16]. Functional status was assessed using the Vulnerable Elders Survey-13 (VAS-13), Katz's Index of Activities of Daily Living $(A D L)$, and Lawton's Scale for Instrumental Activities of Daily Living (IADL) [17-19]. The risk of falls was assessed in the Timed Up and Go test as well as questions on postural instability [20]. The history of falls and injuries during past 12 months was collected. The full version of the Mini Nutritional Assessment questionnaire (MNA) was implemented to rate the risk of malnutrition development. Information regarding the quantity of meals and amount of fluid intake was collected [21].

Additionally, the Pain Assessment Scale (PAS) was used to document the presence and severity of chronic pain [22]. The self-rated health was assessed by the Visual Analogue Scale (VAS) [23]. The prevalence of vaccination among old adults was also studied. There was a separate section dedicated to behavioural risks: tobacco smoking and frequency of alcohol consumption.

\section{Socio-economic Questionnaire}

This part included questions concerning personal and family situation, size and structure of the household, family, and social network. The assessment also covered information about help needed and the family's capacity to provide care for the needs of respondents, as well as the degree of needs coverage. The accessibility, utilisation, and satisfaction with healthcare and social services were assessed. The issue of discrimination against the elderly in healthcare institutions was studied. Respondents were asked about their opinion on the beginning of old age, the main problems affecting seniors, and actions taken to prepare for their upcoming old age. Attention was paid to the level of occupational activity of the participants (past and current). Respondents were asked about leisure time activities, hobbies, and social life. A separate part was devoted to sport and physical activity and motivation for physical performance as well as reasons for its absence. The Seven-Day Physical Activity Recall Questionnaire (PAR) was used to estimate an individual's duration and intensity of physical activities during the week prior to the interview [24].

Another part of the questionnaire was dedicated to the evaluation of financial status and the ability to manage finances as well as meeting financial needs. The survey of housing situation includes the description of the apartment, its size and technical condition, architectural barriers, media, and household appliances.

Quality of life was evaluated using a standardised tool dedicated to old people (WHOQOLAGE) [25]. The study also referred to the issue of violence towards senior citizens. The socio-economic part of the survey included questions concerning use of the Internet as well as IT devices.

\section{Self-completed questionnaire}

At the end of the first visit the respondents were asked to fill in on their own the Pittsburgh Sleep Quality Index (PSQI) [26], the Short Michigan Alcoholism Screening Test (SMAST) [27], and the International Prostate Symptom Score (IPSS) in men only [28]. The nutritional assessment based on the frequency of consuming selected products and dishes was performed. Additionally, the respondents were asked about aspects of religious life and the Internet usage in health matters.

\section{Measurements}

\section{Blood pressure}

An automatic oscillometric device (AND UM211) equipped with three cuffs for different arm circumferences was used to measure arterial BP and pulse [29]. The measurements were performed three times during each of the first and the third visits. Each measurement was taken on the right upper arm, after at least 5 min of rest 
and at 2-min intervals. The participant was in a seated position or lying if bedridden.

\section{Anthropometric parameters}

Waist, hip, and calf circumferences, as well as height without shoes, were measured using a metre scale with the accuracy of $0.5 \mathrm{~cm}$. To determine weight and body composition, a segmental analyser (TANITA BC-545N) was applied. The measurement was performed with bare feet, and body mass, total body water, fat mass, and muscle mass with an accuracy of $0.1 \mathrm{~kg}$ were noted.

\section{Hand grip strength}

To determine the maximum isometric strength of the hand and forearm muscles a hydraulic hand dynamometer (Saehan-SH5001) was used. The measurements were performed three times for each hand at 1-min intervals.

\section{Physical performance}

The Short Physical Performance Battery (SPPB) to check body balance, short-walk speed, and ability to stand up and sit down from a chair five times in a row as quickly as possible was executed during the first visit [30]. Additionally, the Timed Up and Go Test (TUG) was conducted during the second visit. Time was measured by stopwatch with an accuracy of $0.1 \mathrm{~s}$.

\section{Biological material}

Thirty-four millilitres of venous blood and $20 \mathrm{ml}$ of urine were collected during the second visit after at least $8 \mathrm{~h}$ of fasting, using a vacuum tube system. Samples were delivered within $2 \mathrm{~h}$ to local laboratories, where complete blood count (CBC) was performed, and serum/plasma was separated. All blood (supernatants and pellets) and urine samples were frozen and transported on dry ice to the central laboratory where all the tests were performed. The remaining biological material was deep-frozen and stored for further assessments. The results of blood analysis were sent to the respondents. If the results showed significantly out-of-reference values a letter was sent to consult a family physician for advice. The list of study parameters and the methods of assessment are presented in Table I.

\section{Database and statistical issues}

To collect data in the PolSenior2 study the authors used the Medical 4.0 (a web-based eCRF) system with a digital pathway created for this purpose. The data collection system has been described in detail elsewhere [31]. The data from the PolSenior2 Survey underwent a pseudonymis- ation process according to the European Union's new General Data Protection Regulation. Personal data were separated from medical and social data collected during the Survey. Only the Institution Data Protection Supervisor had access to the database with personal data and could re-identify participants if necessary. Researchers and other staff have access only to the anonymised database. Thanks to this, they are not able to re-identify subjects in an anonymised dataset.

As the study analyzed equal strata of age groups, the sample did not reflect the structure of the elderly population (60 and older). The design effect was equal to the reciprocal of the dwelling sampling fraction in the h-th stratum. Weights were adjusted with the use of non-response rates estimated separately for each stratum. The strata were defined by age, gender and the size of residence municipality according to the Polish population structure in 2016.

\section{Results}

In the PolSenior2 study a group of 5987 subjects underwent the questionnaire parts of the survey, geriatric tests, as well as anthropometric and BP measurements. Almost all (97.3\%) agreed to blood or urine sample collection. The sociodemographic characteristics of the study sample are presented in Table II. The results of the study will be available for national and international researchers at the beginning of 2021 at https:// polsenior2.gumed.edu.pl/45587.html.

\section{Discussion}

During the last five decades, as in other developed countries, a number of studies concerning a variety of issues related to ageing of the society were performed in Poland. However, only few of them were carried out on representative samples of older individuals. The first national interdisciplinary gerontological study devoted to the socioeconomic situation and health status of subjects in Poland was carried in the late 1960s [32]. It was performed on a representative sample of 2714 individuals aged 65 years and more. The next surveys examining the living conditions of old persons were performed by Statistics Poland - GUS (Gtówny Urząd Statystyczny) [33, 34]. In those questionnaire-based studies the seniors were asked to self-rate their health (SRH), fitness, and need for assistance. The study performed by the Institute of Public Affairs on a group of 1000 elderly persons provided knowledge on the utilisation and availability of healthcare services [35]. Similarly to the GUS surveys, there was no health examination component including biochemical tests, objective anthropometric and BP measurements, or standardised geriatric scales. 
Health status and its socio-economic covariates in the older population in Poland - the assumptions and methods of the nationwide, cross-sectional PolSenior2 survey

Table I. Blood and urine parameters analysed in the study including methods of assessment

\begin{tabular}{|c|c|c|c|c|}
\hline Parameter & $\begin{array}{l}\text { Biologic } \\
\text { material }\end{array}$ & Method of assessment & $\begin{array}{c}\text { Assay kit } \\
\text { catalogue } \\
\text { number }\end{array}$ & $\begin{array}{c}\text { Accuracy } \\
(\%)\end{array}$ \\
\hline Complete blood count & Blood & Various automated haematology analysers & $\mathrm{n} / \mathrm{a}$ & $\mathrm{n} / \mathrm{a}$ \\
\hline Glycated haemoglobin* & Blood & HPLC & $2702455 \mathrm{EX}$ & 0.24 \\
\hline Fasting glucose & $\begin{array}{l}\text { Fluoride } \\
\text { plasma }\end{array}$ & Enzymatic (hexokinase) & 11097592 & 1.1 \\
\hline Intact parathyroid hormone & $\begin{array}{l}\text { EDTA } \\
\text { plasma }\end{array}$ & Chemiluminescent immunoassay & 10995621 & 3.4 \\
\hline Total cholesterol & Serum & Enzymatic (cholesterol esterase) & 11097609 & 1.3 \\
\hline LDL-cholesterol & Serum & Enzymatic (cholesterol oxidase) & 11097632 & 1.6 \\
\hline HDL-cholesterol & Serum & Enzymatic (cholesterol esterase) & 11097630 & 1.6 \\
\hline Triglycerides & Serum & Enzymatic (glycerol phosphate oxidase) & 11097591 & 2.5 \\
\hline Creatinine & Serum & Enzymatic (creatinine hydrolase) & 11097533 & 2.5 \\
\hline Uric acid & Serum & Enzymatic (uricase) & 11097608 & 1.5 \\
\hline Bilirubin & Serum & Spectrophotometric & 11097531 & 6.3 \\
\hline Alanine transaminase & Serum & Spectrophotometric & 11097605 & 2.8 \\
\hline Aspartate transaminase & Serum & Spectrophotometric & 11097607 & 1.7 \\
\hline$\gamma$-glutamyl transferase & Serum & Spectrophotometric & 11097597 & 1.5 \\
\hline Alkaline phosphatase & Serum & Spectrophotometric & 11097600 & 1.3 \\
\hline Phosphates & Serum & Spectrophotometric & 11097611 & 4.6 \\
\hline Total calcium & Serum & Spectrophotometric & 11097644 & 1.5 \\
\hline Iron & Serum & Spectrophotometric & 11097601 & 2.6 \\
\hline Albumin & Serum & Spectrophotometric & 11097590 & 2.4 \\
\hline Transferrin & Serum & Immunoturbidimetric & 11097613 & 1.9 \\
\hline C-reactive protein & Serum & Immunoturbidimetric (high sensitivity) & 11097633 & 7.4 \\
\hline Cystatin $C^{\star *}$ & Serum & Nephelometric & OQNM17 & 4.3 \\
\hline 25 -hydroksy vitamin $D$ & Serum & Chemiluminescent immunoassay & 10995719 & 8.0 \\
\hline Vitamin $B_{12}$ & Serum & Chemiluminescent immunoassay & 10995714 & 6.4 \\
\hline Folic acid & Serum & Chemiluminescent immunoassay & 10995572 & 7.1 \\
\hline Insulin & Serum & Chemiluminescent immunoassay & 10995628 & 3.6 \\
\hline C-peptide & Serum & Chemiluminescent immunoassay & 10995541 & 4.9 \\
\hline Thyroid-stimulating hormone & Serum & Chemiluminescent immunoassay & 10995703 & 3.7 \\
\hline $\begin{array}{l}\text { Anti-thyroid peroxidase } \\
\text { antibodies }\end{array}$ & Serum & Chemiluminescent immunoassay & 10995466 & 7.4 \\
\hline $\begin{array}{l}\text { Total prostate specific } \\
\text { antigen }{ }^{\star * \star}\end{array}$ & Serum & Chemiluminescent immunoassay & 10995662 & 8.5 \\
\hline HBs antigen & Serum & Chemiluminescent immunoassay & 10995604 & 7.5 \\
\hline anti-HBs antibodies & Serum & Chemiluminescent immunoassay & 10995453 & 5.3 \\
\hline Anti-HBc antibodies & Serum & Chemiluminescent immunoassay & 10995597 & 9.5 \\
\hline Anti-HCV antibodies & Serum & Chemiluminescent immunoassay & 10995456 & 11.5 \\
\hline Albumin & Urine & Immunoturbidimetric & 11097610 & 3.6 \\
\hline Creatinine & Urine & Enzymatic (creatinine hydrolase) & 11097533 & 3.2 \\
\hline
\end{tabular}

${ }^{\star} \mathrm{HbA}$ assays were made on Biorad kits, all others blood and urine analysis were performed using Siemens Healthcare kits; ${ }^{* *}$ in subject with G GFR $<60 \mathrm{ml} / \mathrm{min} / 1.73 \mathrm{~m}^{2}$; ***only in men. 
Ł. Wierucki, H. Kujawska-Danecka, M. Mossakowska, T. Grodzicki, P. Błędowski, J. Chudek, T. Kostka, A. Więcek, A. Hajduk, P. Bandosz, P. Zagożdżon, B. Wojtyniak, T. Zdrojewski

Table II. Sociodemographic characteristics of PolSenior2 study group

\begin{tabular}{|c|c|c|c|}
\hline Parameter & Women $(N=3057)$ & Men $(N=2930)$ & Total $(N=5987)$ \\
\hline \multicolumn{4}{|l|}{ Age cohorts [years]: } \\
\hline $60-64$ & $493(16.1 \%)$ & $437(14.9 \%)$ & $930(15.5 \%)$ \\
\hline $65-69$ & $594(19.4 \%)$ & $525(17.9 \%)$ & 1119 (18.7\%) \\
\hline $70-74$ & $512(16.7 \%)$ & $540(18.4 \%)$ & $1052(17.6 \%)$ \\
\hline $75-79$ & $455(14.9 \%)$ & $455(15.5 \%)$ & $910(15.2 \%)$ \\
\hline $80-84$ & $437(14.3 \%)$ & 409 (14.0\%) & $846(14.1 \%)$ \\
\hline $85-89$ & $320(10.5 \%)$ & $294(10.0 \%)$ & $614(10.3 \%)$ \\
\hline$\geq 90$ & $246(8.0 \%)$ & $270(9.2 \%)$ & $516(8.6 \%)$ \\
\hline \multicolumn{4}{|l|}{ Education: } \\
\hline No education & $58(1.9 \%)$ & $20(0.7 \%)$ & $78(1.3 \%)$ \\
\hline Primary (incomplete) & $79(2.6 \%)$ & $43(1.5 \%)$ & $122(2.0 \%)$ \\
\hline Primary & $869(28.4 \%)$ & $642(21.9 \%)$ & $1511(25.2 \%)$ \\
\hline Middle: gymnasium & $12(0.4 \%)$ & $5(0.2 \%)$ & $17(0.3 \%)$ \\
\hline Middle: vocational school & $557(18.2 \%)$ & $880(30.0 \%)$ & $1437(24.0 \%)$ \\
\hline Secondary & $911(29.8 \%)$ & $774(26.4 \%)$ & $1685(28.1 \%)$ \\
\hline Post-secondary & $154(5.1 \%)$ & $78(2.6 \%)$ & $232(3.9 \%)$ \\
\hline Tertiary: bachelor's, engineer's degree & $116(3.8 \%)$ & $222(7.6 \%)$ & $338(5.7 \%)$ \\
\hline Tertiary: master's degree & $236(7.7 \%)$ & $210(7.2 \%)$ & $446(7.5 \%)$ \\
\hline No data & $65(2.1 \%)$ & $56(1.9 \%)$ & $121(2.0 \%)$ \\
\hline \multicolumn{4}{|l|}{ Place of residence: } \\
\hline Village & $1083(35.4 \%)$ & $1022(34.9 \%)$ & $2105(35.2 \%)$ \\
\hline City $<50$ thou. & $781(25.5 \%)$ & $720(24.6 \%)$ & $1501(25.1 \%)$ \\
\hline City 50-200 thou. & $559(18.3 \%)$ & $596(20.3 \%)$ & $1155(19.3 \%)$ \\
\hline City $>200$ thou. & $634(20.7 \%)$ & $592(20.2 \%)$ & $1226(20.5 \%)$ \\
\hline \multicolumn{4}{|l|}{ Macroregions: } \\
\hline Południowy & $611(20.0 \%)$ & $643(21.9 \%)$ & $1254(20.9 \%)$ \\
\hline Północno-zachodni & $445(14.6 \%)$ & $451(15.4 \%)$ & $896(15.0 \%)$ \\
\hline Południowo-zachodni & $364(11.9 \%)$ & $314(10.7 \%)$ & $678(11.3 \%)$ \\
\hline Północny & $453(14.8 \%)$ & $413(14.1 \%)$ & $866(14.5 \%)$ \\
\hline Centralny & $302(9.9 \%)$ & $292(10.0 \%)$ & $594(9.9 \%)$ \\
\hline Wschodni & $441(14.4 \%)$ & $430(14.7 \%)$ & $871(14.5 \%)$ \\
\hline Województwo mazowieckie & $441(14.4 \%)$ & $387(13.2 \%)$ & $828(13.8 \%)$ \\
\hline \multicolumn{4}{|l|}{ Marital status: } \\
\hline Single & $99(3.2 \%)$ & $80(2.7 \%)$ & $179(3.0 \%)$ \\
\hline Divorced or separated & $142(4.7 \%)$ & $84(2.9 \%)$ & $226(3.8 \%)$ \\
\hline Widowed & $1420(46.5 \%)$ & $480(16.4 \%)$ & $1900(31.7 \%)$ \\
\hline Married & $1309(42.8 \%)$ & $2206(75.3 \%)$ & $3515(58.7 \%)$ \\
\hline No data & $87(2.8 \%)$ & $80(2.7 \%)$ & $167(2.8 \%)$ \\
\hline \multicolumn{4}{|l|}{ Living arrangements: } \\
\hline Alone & $848(29.2 \%)$ & $365(13.0 \%)$ & $1213(21.3 \%)$ \\
\hline With spouse & $1271(43.9 \%)$ & $2169(77.7 \%)$ & $3440(60.5 \%)$ \\
\hline $\begin{array}{l}\text { With children, grandchildren, great- } \\
\text { grandchildren }\end{array}$ & $1140(39.5 \%)$ & $894(32.1 \%)$ & $2034(35.9 \%)$ \\
\hline With other family members & $105(3.7 \%)$ & $130(4.7 \%)$ & $235(4.2 \%)$ \\
\hline No data & $153(5.0 \%)$ & $132(4.5 \%)$ & $285(4.8 \%)$ \\
\hline
\end{tabular}


An important national gerontological study carried out on a representative sample of 1800 seniors in the project entitled Polska starość [Polish Old Age] [36] was performed from 1999 to 2001. Information on the prevalence of chronic health conditions in the elderly can also be acquired from the regular Polish censuses with obligatory participation. The last Polish Census carried out in 2011 collected data concerning disability [37]. In 2016, a report Informacja o sytuacji osób starszych na podstawie badań Głównego Urzędu Statystycznego [Information on the Situation of Elderly Persons on the Basis of Research by the Central Statistical Office] was published, providing data on self-rated health (SRH), the prevalence of chronic diseases, vision and hearing impairments, as well as mobility, independence, the utilisation and availability of medical services, and preventive health behaviours.

Apart from projects dedicated to older persons, nationwide surveys enrolling individuals in a wide age span including older adults were performed in Poland. The first NATPOL survey in 1997 resulted in assessment of the prevalence and control of hypertension in a population aged 65 years and more [38]. The series of the NATPOL 1997, NATPOL PLUS 2002, NATPOL 2011 [39], as well as WOBASZ-Senior, WOBASZ I, and WOBASZ II surveys [40] increased the knowledge on the prevalence, risk factors, and treatment of cardiovascular disease in the Polish population, including reasonable but relatively small cohorts of older adults.

There are also some international studies with Polish participation. The common research methodology used in these projects enables the direct comparison of results between countries. The Survey of Health, Ageing, and Retirement in Europe (SHARE) is a multidisciplinary study carried out as of 2004 in Europe and Israel on individuals aged $50+$ years and their partners. The study focuses on health and the use of healthcare, socioeconomic status, professional activity, social networks, and family relations. It is based on experience from the English Longitudinal Study of Ageing (ELSA) [41] and The Irish Longitudinal Study on Ageing (TILDA) [42]. There have been eight waves of SHARE so far, and wave 9 is currently in progress. The study is repeated every 2 years, which enables perception of the dynamics of changes taking place in the ageing societies. Data has been collected from more than 120,000 citizens from 27 European countries and Israel. Along with interviews, tests evaluating the respondent's cognitive functions, mental health, and physical fitness are also conducted. This is a longitudinal study that includes the option of supplementing the primary sample [43]. A project summary from the perspective of Polish researchers (since 2006/2007) was recently published as the report edited by Myck and Oczkowska [44].
In addition, the Jagiellonian University in Krakow participated in the Collaborative Research on Ageing in Europe (COURAGE in EUROPE). The project was implemented between 2009 and 2012 in four countries: Finland, Italy, Poland, and Spain, and was supported by the World Health Organisation. It was aimed at the development and validation of assessment tools, and the performance of cross-population analyses. In Poland, 4071 individuals $(74.4 \%$ of them aged 50 years or more) participated in the survey. The study focused on their socio-demographic status, health, healthcare services utilisation, social cohesion, social networks, welfare, quality of life, and built environment [45, 46]. Anthropometric and BP measurements were carried out, and walking speed, grip strength, vision, and cognitive functions were tested.

Among population surveys, PolSenior1 (20072011) was the largest and the most comprehensive study devoted to the health status of older persons in Poland. It was based on equinumerous 5 -year age cohorts with similar proportions of men and women. Such a study design resulted in a large subgroup of very old subjects, which is usually small in cross-sectional studies, which made it possible to draw conclusions concerning differences between early and advanced old age [47]. Unfortunately, we did not receive any grant to perform a longitudinal study of the PolSenior1 cohort, and therefore the analyses conducted at present are based on tracing all-cause mortality.

The methodology of PolSenior2 and PolSenior 1 is similar. However, in the study protocol of PolSenior2, the geriatric examination was withdrawn. In the PolSenior1 almost 1000 respondents were examined at home by geriatricians, but due to the very high cost of such a procedure and low representativeness (respondents with poor general condition more frequently refused to undergo the examination) it has not been included in the PolSenior2 protocol. The PolSenior2 protocol did not include residents of nursing homes. There was only $1.1 \%$ of such participants in the PolSenior 1 study, which was a significantly smaller percentage compared to the $2.4 \%$ found in a survey performed among older Americans [48].

There are two new procedures implemented in the present study protocol: the grip strength and the Short Physical Performance Battery, which will allow for an objective assessment of mobility and the prevalence of frailty, which was missing in the previous project. In addition, the Polish version of the Duke University Religion Index was included in a set of social questions [49].

There is no doubt that assessment of a new cohort (PolSenior2) after a decade will allow the trends in health, health-related behaviours, and the social situation of seniors taking place in the rapidly ageing Polish society to be seen. Compar- 
ing age cohorts from both the PolSenior1 and Polsenior2 studies, we may evaluate the effectiveness of screening and other preventive interventions considering the 10-year lag time of its outcome [50]. The collected biological material will facilitate the search for new markers and the testing of the usefulness of known and potential markers of successful ageing, also in cooperation with leading international centres. This study represents all regions of Poland, and therefore has the potential to identify spatial differentiation of morbidities in the Polish elderly population [51].

The response rate in the initial PolSenior study was $43 \%$, whereas in the Polsenior2 it reached $56 \%$. Taking into account the respondents who could not be reached at home (no one opened the door), the number would be $37 \%$. It was assumed that the situation in which it is not possible to submit a proposal to participate due to the absence of the respondent is similar to situations in which it is known that the respondent has moved out or is permanently staying at another address. The dynamically changing social conditions observed for a number of years in Poland have contributed to increased migration and mobility of older people and their families. Another problem is a constant decline of the readiness of the Polish population, in particular older adults, to participate in surveys and other research projects. A decrease in the effectiveness of research requiring a stranger's visit at home has been observed previously in western countries $[52,53]$. It was noted by Gao et al. that women were present at the indicated address less often than men. Moreover, it was harder to access respondents living in buildings with increased security (concierge, fenced estates) and those with lower social status [54]. There is no existing consensus on the acceptable non-response level (non-response bias). It is, however, customary that an approximate description of those who refuse to participate is required to assess the quality of the study [55]. Most researchers agree that a participation rate above $50 \%$ should be considered a success [56].

A cross-sectional study design can assess the prevalence of certain health outcomes in relation with the prevalence of certain putative risk factors at a given point of time, but its causal and temporal relationship may be difficult to interpret, which may be particularly relevant in old age [57]. As such, the PolSenior2 cohort will be the basis for longitudinal studies on ageing as well as for analyses concerning changes in the medical and nursing care needs. The PolSenior2 study will also allow the estimation of the demand for institutional and home-based, nurse-led health care services, in response to the declining level of mobility and mental functioning of ageing population of Poland. The most important determinants of nursing care use and declining quality of life in older age are not only medical conditions but also worsening functional status, chronic pain [58], poor nutrition [59], and low physical activity [60], which are extensively analysed in this study.

Finally, one of the most significant outcomes of the PolSenior2 study will be recommendations worked out for senior policy for the state government, local administration, and NGOs. It may also raise public awareness concerning the main issues of healthy ageing.

\section{Declarations}

\section{Ethical approval and consent to participate}

The PolSenior2 project meets the ethical requirements of the European Union (Directive 2001/20/EC) and was approved by the Independent Bioethics Commission of the Medical University of Gdansk (NKBBN/257/2017). The approval concerned the recruitment, field work (questionnaires, tests, and measurements), and collection and storage of biological material. Before a nurse visit, each respondent received a letter of invitation with a description of the project. Additional information was included in the informed consent forms signed by the participants or their caregivers at the beginning of the first visit. A separate agreement was signed to draw blood and store biological material for further studies, including genomic research. The lack of agreement for blood/urine sample collection did not exclude the respondent from participating in the project. Each respondent was assigned a unique identification number to ensure confidentiality of personal data collected during the survey. All blood and urine samples were coded with the same number.

\section{Acknowledgments}

The authors would like to express their deepest gratitude to all members and associates of the PolSenior2 Project: survey takers, nurses who did fieldworks, employees of the 'Pracownia Badan Marketingowych Wołkiewicz', employees of ALAB Group, employees of the Ministry of Health, members of administrative staff and students from Medical University of Gdańsk, as well as all experts and associates of the PolSenior2 research team from (in alphabetical order): Geriatric Hospital of the name John Paul II in Katowice, International Institute of Molecular and Cell Biology in Warsaw, Jagiellonian University Medical College, Kozminski University, Medical University of Gdańsk, Medical University of Lodz, Medical University of Warsaw, Mossakowski Medical Research Centre Polish Academy of Sciences in Warsaw, Poznan University of Medical Science. Without their efforts and support the PolSenior2 project in its shape would not be possible. 
Łukasz Wierucki and Hanna Kujawska-Danecka - equal contribution to this work.

\section{Conflict of interest}

The authors declare no conflict of interest.

\section{References}

1. OECD OECD: Health at a Glance 2017: OECD Indicators, OECD Publishing, Paris. http://dx.doi.org/10.1787/ health_glance-2017-en.

2. [Changes in structure of population aged 65 and more]. In: [Population forecast for 2014-2050], Polish. Warszawa: GUS, Departament Badań Demograficznych i Rynku Pracy. The publication is available on http://www.stat. gov.pl/; 2014.

3. Pobrotyn P, Susło R, Witczak IT, Rypicz Ł, Drobnik J An analysis of the costs of treating aged patients in a large clinical hospital in Poland under the pressure of recent demographic trends. Arch Med Sci 2020; 16: 666-71.

4. Piotrowicz K, Pac A, Skalska AB, et al. Clustering of geriatric deficits emerges to be an essential feature of ageing - results of a cross-sectional study in Poland. Aging (Albany NY) 2016; 8: 2437-48.

5. Helthy Life Years data. Eurostat. https://ec.europa.eu/ eurostat/data/database. Accesed 1 Apr 2019.

6. Gnanadesigan N, Fung CH. Quality indicators for screening and prevention in vulnerable elders. J Am Geriatr Soc 2007; 55 Suppl 2: S417-23.

7. Artaud F, Dugravot A, Sabia S, Singh-Manoux A, Tzourio $C$, Elbaz A. Unhealthy behaviours and disability in older adults: three-City Dijon cohort study. BMJ 2013; 347: $f 4240$.

8. Bledowski P, Mossakowska M, Chudek J, et al. Medical, psychological and socioeconomic aspects of aging in Poland: assumptions and objectives of the PolSenior project. Exp Gerontol 2011; 46: 1003-9.

9. Cruz-Jentoft AJ, Landi F, Topinkova E, Michel JP. Understanding sarcopenia as a geriatric syndrome. Curr Opin Clin Nutr Metab Care 2010; 13: 1-7.

10. Cruz-Jentoft AJ, Baeyens JP, Bauer JM, et al. Sarcopenia: European consensus on definition and diagnosis: Report of the European Working Group on Sarcopenia in Older People. Age Ageing 2010; 39: 412-23.

11. Fried LP, Tangen CM, Walston J, et al. Frailty in older adults: evidence for a phenotype. J Gerontol A Biol Sci Med Sci 2001; 56: M146-56.

12. Gielen E, Verschueren S, O'Neill TW, et al. Musculoskeletal frailty: a geriatric syndrome at the core of fracture occurrence in older age. Calcif Tissue Int 2012; 91: 161-77.

13. [Demographic Yearbook of Poland] Polish. Warszawa: Główny Urząd Statystyczny; 2018.

14. Folstein MF, Folstein SE, McHugh PR. "Mini-mental state". A practical method for grading the cognitive state of patients for the clinician. J Psychiatr Res 1975; 12: 189-98.

15. Dal Pan G, Stern Y, Sano M, Mayeux R. Clock-drawing in neurological disorders. Behav Neurol 1989; 2: 39-48.

16. Sheikh JI, Yesavage JA, Brooks JO $3^{\text {rd }}$, et al. Proposed factor structure of the Geriatric Depression Scale. Int Psychogeriatr 1991; 3: 23-8.

17. Saliba D, Elliott M, Rubenstein LZ, et al. The Vulnerable Elders Survey: a tool for identifying vulnerable older people in the community. J Am Geriatr Soc 2001; 49: 1691-9.
18. Lawton MP, Brody EM. Assessment of older people: self-maintaining and instrumental activities of daily living. Gerontologist 1969; 9: 179-86.

19. Katz S, Downs TD, Cash HR, Grotz RC. Progress in development of the index of ADL. Gerontologist 1970; 10: 20-30.

20. Podsiadlo D, Richardson S. The timed "Up \& Go": a test of basic functional mobility for frail elderly persons. J Am Geriatr Soc 1991; 39: 142-8.

21. Vellas B, Guigoz Y, Garry PJ, et al. The Mini Nutritional Assessment (MNA) and its use in grading the nutritional state of elderly patients. Nutrition 1999; 15: 116-22.

22. Kozak-Szkopek E, Broczek K, Slusarczyk P, et al. Prevalence of chronic pain in the elderly Polish population results of the PolSenior study. Arch Med Sci 2017; 13: 1197-206.

23. Szybalska A, Broczek K, Puzianowska-Kuznicka M, et al. Self-rated health and its association with all-cause mortality of older adults in Poland: the PolSenior project. Arch Gerontol Geriatr 2018; 79: 13-20.

24. Blair SN, Haskell WL, Ho P, et al. Assessment of habitual physical activity by a seven-day recall in a community survey and controlled experiments. Am J Epidemiol 1985; 122: 794-804.

25. Caballero FF, Miret M, Power M, et al. Validation of an instrument to evaluate quality of life in the aging population: WHOQOL-AGE. Health Qual Life Outcomes 2013; 11: 177 .

26. Buysse DJ, Reynolds CF $3^{\text {rd }}$, Monk TH, Berman SR, Kupfer DJ. The Pittsburgh Sleep Quality Index: a new instrument for psychiatric practice and research. Psychiatry Res 1989; 28: 193-213.

27. Selzer ML, Vinokur A, van Rooijen L. A self-administered Short Michigan Alcoholism Screening Test (SMAST). J Stud Alcohol 1975; 36: 117-26.

28. Barry MJ, Fowler FJJ, O'Leary MP, et al. The American Urological Association symptom index for benign prostatic hyperplasia. The Measurement Committee of the American Urological Association. J Urol 1992; 148: 1549-57.

29. Fania C, Albertini F, Palatini P. Validation of the $A \& D$ UM-211 device for office blood pressure measurement according to the European Society of Hypertension International Protocol revision 2010. Blood Press Monit 2017; 22: 302-5.

30. Guralnik JM, Simonsick EM, Ferrucci L, et al. A short physical performance battery assessing lower extremity function: association with self-reported disability and prediction of mortality and nursing home admission. J Gerontol 1994; 49: M85-94.

31. Labuda N, Lepa T, Labuda M, Kozak K. Medical 4.0: Medical Data Ready for Deep and Machine Learning. J Bioanal Biomed 2017; 9: 283-7.

32. Piotrowski J. Place of an old people in the family and society. PWN, Warsaw 1973.

33. Social situation of elderly people in the year 1985. In: Statistics Poland. Główny Urząd Statystyczny, Warsaw 1985.

34. Social situation of elderly people in the year 1989. In: Statistics Poland. Gtówny Urząd Statystyczny, Warsaw 1990.

35. Halik J. Old people in Poland. Health and social consequences of population aging. ISP, Warsaw 2002.

36. Synak B. Polish old age. Wydawnictwo Uniwersytetu Gdańskiego, Gdańsk 2002.

37. National Censuses. http://stat.gov.pl/spisy-powszechne/ nsp-2011/nsp-2011-wyniki/ 
38. Kąkol M, Zdrojewski T, Kozicka-Kąkol K, Pieńkowski R, Wyrzykowski B, Krupa-Wojciechowska B. Prevalence, awareness and efficacy of treatment of hypertension in older people in Poland - assessment by a representative survey. Gerontol Pol 1999; 7: 23-9.

39. Zdrojewski T, Rutkowski M, Bandosz P, et al. Assessment of prevalence and control of risk factors for cardiovascular disease in Poland - NATPOL 1997, 2002, 2011. In: Epidemiology and prevention of cardiovascular disease. Kopeć G, Jankowski P, Pająk A, Drygas W (eds). Medycyna Praktyczna, Kraków 2015; 57-64.

40. Drygas W, Niklas AA, Piwonska A, et al. Multi-centre National Population Health Examination Survey (WOBASZ Il study): assumptions, methods, and implementation. Kardiol Pol 2016; 74: 681-90.

41. Marmot M, Banks J, Blundell R, Lessof C, Nazroo J. Health, Wealth and Lifestyles of the Older Population in England. The 2002 English Longitudinal Study of Ageing. In. London: Institute for Fiscal Studies; 2003.

42. The Design of the Irish Longitudinal Study on Ageing: TILDA. http://tilda.tcd.ie/about/

43. SHARE - Survey of Health, Ageing and Retirement in Europe. http://www.share-project.org/

44. Myck M, Oczkowska M. Generation 50+ in Poland versus Europe: activity, health and quality of life. Results based on the SHARE study. CenEA Economic Analysis Center. Centrum Analiz Ekonomicznych CenEA 2017; 1-129.

45. Perales J, Martin S, Ayuso-Mateos JL, et al. Factors associated with active aging in Finland, Poland, and Spain. Int Psychogeriatr 2014; 26: 1363-75.

46. Tobiasz-Adamczyk B, Galas A, Zawisza K, et al. Gender-related differences in the multi-pathway effect of social determinants on quality of life in older age-the COURAGE in Europe project. Qual Life Res 2017; 26: 1865-78.

47. Zdrojewski T, Wizner B, Wiecek A, et al. Prevalence, awareness, and control of hypertension in elderly and very elderly in Poland: results of a cross-sectional representative survey. J Hypertens 2016; 34: 532-8.

48. Cigolle CT, Langa KM, Kabeto MU, Tian Z, Blaum CS Geriatric conditions and disability: the Health and Retirement Study. Ann Intern Med 2007; 147: 156-64.

49. Dobrowolska B, Jurek K, Pilewska-Kozak AB, Pawlikowski J, Drozd M, Koenig H. Validation of the Polish version of the Duke University Religion Index (PolDUREL). Pol Arch Med Wewn 2016; 126: 1005-8.

50. Lee SJ, Leipzig RM, Walter LC. Incorporating lag time to benefit into prevention decisions for older adults. JAMA 2013; 310: 2609-10.

51. Clark SD, Birkin M, Heppenstall A. Sub regional estimates of morbidities in the English elderly population. Health Place 2014; 27: 176-85.

52. Galea S, Tracy M. Participation rates in epidemiologic studies. Ann Epidemiol 2007; 17: 643-53.

53. Mindell JS, Giampaoli S, Goesswald A, et al. Sample selection, recruitment and participation rates in health examination surveys in Europe: experience from seven national surveys. BMC Med Res Methodol 2015; 15: 78.

54. Gao L, Green E, Barnes LE, et al. Changing non-participation in epidemiological studies of older people: evidence from the Cognitive Function and Ageing Study I and II. Age Ageing 2015; 44: 867-73.

55. Morton SM, Bandara DK, Robinson EM, Carr PE. In the 21 st Century, what is an acceptable response rate? Aust N Z J Public Health 2012; 36: 106-8.

56. Tolonen H, Ahonen S, Jentoft S, Kuulasmaa K, Heldal J. European Health Examination Pilot P Differences in par- ticipation rates and lessons learned about recruitment of participants: the European Health Examination Survey Pilot Project. Scand J Public Health 2015; 43: 212-9.

57. Brenner $\mathrm{H}$, Arndt V. Epidemiology in aging research. Exp Gerontol 2004; 39: 679-86.

58. Huang YL, Tsay WI, Her SH, et al. Chronic pain and use of analgesics in the elderly: a nationwide population-based study. Arch Med Sci 2020; 16: 627-34.

59. Kostka J, Borowiak E, Kostka T. Nutritional status and quality of life in different populations of older people in Poland. Eur J Clin Nutr 2014; 68: 1210-5.

60. Guligowska AR, Piglowska M, Smigielski J, Kostka T. Inappropriate pattern of nutrient consumption and coexistent cardiometabolic disorders in elderly people from Poland. Pol Arch Med Wewn 2015; 125: 521-31. 